Original Article

\title{
Nutritional Status of Mothers of Well-Nourished Children versus Malnourished Children at Civil Hospital Hyderabad
}

\author{
Bindia Kailash, Salma Shaikh, Muhammad Nadeem Chohan, Muhammad Hanif, \\ Mushtaque Ali Shah
}

\begin{abstract}
OBJECTIVE: To compare the nutritional status by using Body Mass Index (BMI) among Mothers of Well nourished Children versus malnourished children at Civil Hospital Hyderabad

METHODOLOGY: A Comparative/ Analytical observational study conducted at paediatric Department, Unit-I, Civil Hospital Hyderabad from March 2015 to February 2016 in total 384 mothers. Group A and Group B, both had 192 mothers. Group A contain mothers of malnourished children (whose mid upper arm circumference was $<11.5 \mathrm{~cm}$ ) and Group B contain mothers of well-nourished children (whose mid upper arm circumference was $>12.5 \mathrm{~cm}$ ). Body Mass Index of mothers were calculated and classified into normal, mild underweight, moderate and sever underweight.

RESULTS: BMI of mothers of well-nourished children were better than the BMI of mothers of malnourished children. Around $73.9 \%$ mothers of well-nourished children had normal BMI as compared to mothers of malnourished children (10\%). Around $18.2 \%$ mothers of well-nourished children were mildly underweight comparing $41.1 \%$ mothers of malnourished children. Nearly $6.3 \%$ mothers of well-nourished children were moderately underweight while $28.9 \%$ mothers of malnourished children were moderately underweight. More mothers of malnourished children were severely underweight $(20 \%)$ as compared to mothers of well-nourished children (1.6\%).
\end{abstract}

CONCLUSION: In this study, majority of mothers of children with malnutrition had lower Body Mass Index (Underweight), as compared to mothers of well-nourished children.

KEYWORDS: Nutritional Assessment, Body Mass Index, Malnutrition, Nutritional Stabilization Center

This article may be cited as: Kailash B, Shaikh S, Chohan MN, Hanif M, Shah MA. Nutritional Status of Mothers of Well-Nourished Children versus Malnourished Children at Civil Hospital Hyderabad. J Liaquat Uni Med Health Sci. 2019;18(04):276-80.

doi: $10.22442 /$ jlumhs. 191840642

\section{INTRODUCTION}

There are 165 million malnourished children under five years around the globe ${ }^{1}$. Malnutrition accounts for at least half of all childhood deaths worldwide ${ }^{2}$. Child malnutrition is generally only a problem of developing and underdeveloped countries ${ }^{3}$. Pakistan been reported to have one of the highest levels of prevalence of child malnutrition compared to other developing counties ${ }^{4}$. According to the National Nutrition Survey, 33\%of all children were underweight, nearly $44 \%$ were stunted, $15 \%$ are wasted. In the last two decades, there has been a little reduction in the prevalence of child malnutrition in Pakistan compared to other developing countries ${ }^{5,6}$.

Females in the pregnancy stage group and children are at utmost risk toward malnutrition because of little nutritional consumptions, discriminatory conveyance of food inside the household, inappropriate food capacity and preparation, nutritional restrictions and infective diseases. Particularly for young females, the high dietary requirements at productive age and lactation also cause their poor dietary condition ${ }^{7}$.

Various children are born with Low Birth Weight (LBW) due to their mothers' poor dietary status. Approximately, $50 \%$ of stunting takes place in utero ${ }^{8}$. Dietary conditions about mother negotiated via the aggregate and intake of certain supplemental rich foodstuff of mothers ${ }^{9}$. BMl $<18.5 \mathrm{~kg} / \mathrm{m}^{2}$ indicates underweight and demonstrate chronic energy deficiency. In Sub-Sahara Africa $10 \%$ - 20\% of the younger females and in South Asia, $25 \%-35 \%$ of the younger females classified as per similarly thin ${ }^{10}$. Underweight (as contrasted to stunt) mothers are high risk to deliver small babies ${ }^{11}$. Thirty percent mothers are underweight, in the report of Pakistan Panel Household Survey ${ }^{12}$.

This study conducted to assess whether mothers of malnourished children are themselves malnourished. The results of this study may help to focus the whole family especially the mothers, while managing the children with severe acute malnutrition. Early detection and management of malnourished mothers can prevent the malnutrition in their children. 


\section{METHODOLOGY}

This comparative/analytical observational study was conducted at Department of Paediatrics Unit-I, Civil Hospital Hyderabad from March 2015 to February 2016. Total 384 mothers of well-nourished and malnourished children, age 06 to 59 months taken from Paediatric ward for this study. Sample Size was calculated by observance the pervasiveness of Severe Acute Malnutrition, $6 \%$ according to Flood Affected Nutrition Survey (FANS Survey), total under Five Years population is $5174781(17 \%$ of the total population of Sindh $30,439,893$ ) with $95 \%$ confidence level and $5 \%$ as a margin of error ${ }^{23}$. Total 192 mothers of malnourished children (whose MUAC was <11.5 $\mathrm{cm}$ ) compared with 192 mothers of well-nourished children (whose MUAC was $>12.5 \mathrm{~cm}$ ) were taken in this study. Inclusion criteria was Mothers of malnourished children admitted in NSC and Mothers of well-nourished children admitted in ward. Mothers of children with any congenital malformations like cleft palate, Pierre robin syndrome and congenital heart ailments and Mothers of Neonate admitted in nursery excluded from study. Mothers of children having history of repeated illness in the past and history of worms infestations also excluded from the study.

This study conducted after approval from ethical committee at LUMHS Jamshoro. Mothers and children who fulfill the inclusion criteria evaluated in the study. The purpose, procedure and benefits explained and informed consent taken from mothers. Body Mass Index (BMI) of mothers measured and MUAC of children were taken. A standardized questionnaire was used to collect the data included maternal age, $\mathrm{BMI}$ and children demographic features like age and gender as well as MUAC. The Data collected in the study was analyzed by using the SPSS version 18.Categorical variables such as infants and percentages whereas numerical variables such as mothers age and infant's age was expressed in means and standard deviations. Two groups of mothers were compared using a proper analytical test and odds ratio was calculated.

\section{RESULTS}

In this study total 384 children were selected, their age and gender is described in Table I.

Nutritional status of 384 mothers; among them 192 mothers well-nourished children and 192 mothers of malnourished children aged 06 to 59 months were assessed in the nutrition stabilization centre and general ward of Paediatrics department, Liaquat University Hospital. One hundred ninety two mothers of well-nourished children were assessed according to their BMI; $73.9 \%$ of mothers had normal BMI, $18.2 \%$ were mildly underweight, $6.3 \%$ were moderately under weight and $1.6 \%$ were severely underweight. Further more, 192 mothers of malnourished children were measured by their BMI among them $10.41 \%$ had normal BMI, $41.66 \%$ mildly underweight, $27.08 \%$ moderately underweight and $20.83 \%$ were severely underweight Table III. Socio-economic characteristics of mother are present in Table II.

\section{TABLE I: DEMOGRAPHIC DATA OF CHILDREN}

\begin{tabular}{|l|c|c|}
\hline $\begin{array}{c}\text { Malnourished Children } \\
\text { Age (Months) }\end{array}$ & $\begin{array}{c}\text { Number } \\
\text { (total 192) }\end{array}$ & Percentage \\
\hline $6-12$ & 112 & 58.33 \\
\hline $13-36$ & 60 & 31.25 \\
\hline $37-59$ & 20 & 10.41 \\
\hline Sex & 89 & 46.35 \\
\hline Male & 103 & 53.64 \\
\hline Female & $\begin{array}{c}\text { Number } \\
\text { (total 192) }\end{array}$ & Percentage \\
\hline $\begin{array}{l}\text { Well-nourished Children } \\
\text { Age (Months) }\end{array}$ & 34 & 17.70 \\
\hline $6-12$ & 75 & 39.06 \\
\hline $13-36$ & 83 & 43.22 \\
\hline $37-59$ & 91 & 47.39 \\
\hline Sex & 101 & 52.60 \\
\hline Male & \multicolumn{2}{|l}{} \\
\hline Female & &
\end{tabular}

TABLE II: SOCIO-ECONOMIC CHARACTERISTICS OF MOTHER

\begin{tabular}{|l|r|r|}
\hline $\begin{array}{c}\text { Socio-economic } \\
\text { characteristics }\end{array}$ & $\begin{array}{c}\text { Mothers of } \\
\text { Malnourished } \\
\text { Children } \\
\text { (Total } \mathbf{n = 1 9 2 )}\end{array}$ & $\begin{array}{c}\text { Mothers of } \\
\text { Well-nourished } \\
\text { Children } \\
\text { (Total } \mathbf{n = 1 9 2 )}\end{array}$ \\
\hline Educational Level & $\mathbf{n}$ (Percentage) & $\mathbf{n}$ (Percentage) \\
\hline No education & $149(77.60)$ & $68(35.41)$ \\
\hline Primary & $42(21.87)$ & $93(48.43)$ \\
\hline Secondary to higher & $1(0.52)$ & $31(16.14)$ \\
\hline Household Economic Status & \\
\hline Poor Class & $138(71.87)$ & $69(35.93)$ \\
\hline Middle Class & $51(26.56)$ & $101(52.60)$ \\
\hline Rich Class & $3(1.56)$ & $22(11.45)$ \\
\hline
\end{tabular}

\section{DISCUSSION}

In our study total 384 children were included, among them 192 children had malnutrition while 192 were well nourished and admitted in paediatrics ward with complaints other than malnutrition. Among 192 
Bindia Kailash, Salma Shaikh, Muhammad Nadeem Chohan, Muhammad Hanif, Mushtaque Ali Shah

TABLE III: BMI RANGE OBSERVED BETWEEN MOTHERS OF WELL AND MALNOURISHED CHILDREN WITH STATISTICAL TEST

\begin{tabular}{|l|c|c|c|c|}
\hline \multicolumn{1}{|c|}{ BMI Range } & $\begin{array}{c}\text { Mothers of } \\
\text { Well-nourished Children }\end{array}$ & $\begin{array}{c}\text { Mothers of } \\
\text { Malnourished Children }\end{array}$ & Chi-Square & P-Value \\
\hline $\begin{array}{l}18.5-25 \mathrm{~kg} / \mathrm{m} 2 \\
\text { Normal }\end{array}$ & $142(73.95 \%)$ & $20(10.41 \%)$ & & \\
\hline $\begin{array}{l}17-18.49 \mathrm{~kg} / \mathrm{m} 2 \\
\text { Mildly Underweight }\end{array}$ & $35(18.22 \%)$ & $80(41.66 \%)$ & \multirow{2}{*}{0.01} \\
\cline { 1 - 3 } $\begin{array}{l}16-16.9 \mathrm{~kg} / \mathrm{m} 2 \\
\text { Moderately Underweight }\end{array}$ & $12(6.25 \%)$ & $52(27.08 \%)$ & & \\
\cline { 1 - 4 } $\begin{array}{l}<16 \mathrm{~kg} / \mathrm{m} 2 \\
\text { Severely Underweight }\end{array}$ & $3(1.56 \%)$ & $40(20.83 \%)$ & & \\
\hline
\end{tabular}

children having malnutrition, $58.33 \%$ children were between $6-12$ months of age, $31.25 \%$ between $13-36$ months and $10.41 \%$ between $37-59$ months. Among 192 well-nourished children, $17.70 \%$ were between 6-12 months of age, $39.06 \%$ between 13-36 months and $43.22 \%$ between $37-59$ months of age. About $46.35 \%$ malnutrition children were male and $53.64 \%$ were female, while $47.39 \%$ well-nourished children were male and 52.60 were female.

In this study, BMI of Mothers of Well-Nourished Children was normal in $73.9 \%$, mildly underweight in $18.2 \%$, moderate underweight in $6.3 \%$ and severely underweight in $1.6 \%$ women. Regarding BMI of Mothers of Malnourished children, $10 \%$ were normal, $41.1 \%$ were mildly underweight, $28.9 \%$ were moderately underweight and $20 \%$ were severely underweight.

In a different study $42.2 \%$ mothers had low BMI and $13 \%$ of their children under-5 years were observed severely underweight and $34 \%$ of children were moderately underweight ${ }^{13}$. In another study, children of thin mothers were $29 \%$ more likely to be stunted but children of over weight obese mothers were $43 \%$ less likely to be stunted than normal BMI mothers ${ }^{14}$.

A study similar to our study showed, mothers of severely acute malnutrition were underweight in 76 $(50.6 \%)$ cases, out of them $10(6 \%)$ were severely thin, $23(15.3 \%)$ were moderately thin and the rest were mildly thin ${ }^{15}$, while in another study done in mothers of severely acute malnutrition children $33.7 \%$ mothers were underweight ${ }^{16}$. In a study It was noted that underweight is more frequent in children born to underweight mother compared to children born to a normal weight, overweight or obese mother $(B M I \geq 18.5)^{17}$.

A similar study revealed that, there was a significant association between maternal BMI and children nutritional status; it was observed that an increase in BMI status was associated with a lower rate of childhood undernutrition ${ }^{18}$. In another study, an interaction was found between maternal BMI and underweight in children. Children of underweight mothers had a $21 \%$ higher risk of being stunted ${ }^{19}$. An international study showed that mother's BMI had a significant negative effect on child malnutrition, indicating that healthier mothers have less risk of having malnourished children. Children with normal weighted mother had $43 \%$ lower odds of staying in the worst state of nutritional status ${ }^{20}$, while another study shows BMI of mothers of underweight children showed that $24.5 \%$ of mothers were malnourished ${ }^{21}$. A similar study showed positively significant correlations between BMI of children and mothers, $14.2 \%$ of the children were thin, whereas $1.5 \%$ of the mothers were thin ${ }^{22}$.

Maternal educational status is associated with nutritional status of their children because, low educational status reduce the possibility of acquiring healthy foods or lower awareness of the role of food in the future growth of child. As there is close association between maternal and child under nutrition in Pakistan, it needs sustained investments to address social determinants in Pakistan. There should be investments in education and empowerment of girls. In our study, low educational status of mother and poor economic status of family is associated with maternal malnutrition. Among mothers of malnourished Children $77.60 \%$ women did not had even primary education and $71.87 \%$ belonged to poor class status, while $35.41 \%$ Mothers of Well-nourished Children were uneducated and $35.93 \%$ women belonged to poor class status. In a similar international study, there was four-fold higher chance of malnutrition in children whose mothers had low level of schooling and low socioeconomic status ${ }^{24}$. In another study, $14 \%$ mother were illiterate and $58.7 \%$ women took only primary education ${ }^{25}$.

\section{CONCLUSION}

This study shows that significant number of mothers of severely acute malnutrition, they are undernourished. We can conclude that malnutrition is not the issue of 
just child, but it may be the issue of mothers and can be the issue of whole family. Besides managing the admitted child with malnutrition, factors leading to malnutrition should be determined and addressed properly to solve this issue in the whole family.

\section{RECOMMENDATIONS}

On basis of this study results, we recommend that women of child barring age should be assessed for malnutrition by calculating Body Mass Index. By improving the nutritional status of mothers, we can decrease the frequency of malnutrition in children. In case of low socioeconomic status, nutritional counseling should be done regarding cheap high protein food.

Ethical permission: Liaquat University of Medical \& Health Sciences Jamshoro ERC Letter No. LUMHS/ REC/-178, Dated 23-06-2017.

Conflict of Interest: Authors of the study have no conflict of interest to declare.

Funding: There was no funding source.

\section{REFERENCES}

1. Black RE, Victora CG, Walker SP, Bhutta ZA, Christian $\mathrm{P}$, de Onis $\mathrm{M}$, et al. Maternal and child under nutrition and overweight in low-income and middle-income countries. Lancet. 2013; 382 (9890): 427-51. doi: 10.1016/S0140-6736(13) 60937-X.

2. Meshram II, Arlappa N, Balakrishna N, Mallikharjuna Rao K, Laxmaiah A, Brahmam GN. Trends in the prevalence of undernutrition, nutrient and food intake and predictors of undernutrition among under five year tribal children in India. Asia Pac J Clin Nutr. 2012; 21 (4):568-76.

3. Müller $\mathrm{O}$, Krawinkel M. Malnutrition and health in developing countries. CMAJ. 2005; 173(3): 27986. doi: $10.1503 / \mathrm{cmaj} .050342$.

4. Di Cesare M, Bhatti Z, Soofi SB, Fortunato L, Ezzati M, Bhutta ZA. Geographical and socioeconomic inequalities in women and children's nutritional status in Pakistan in 2011: an analysis of data from a nationally representative survey. Lancet Glob Health. 2015; 3(4): e229-e39. doi: 10.1016/S2214-109X(15)70001-X.

5. Bhutta Z, Soofi S, Zaidi S, Habib A, Hussain M. Pakistan National Nutrition Survey 2011. Available from: https://ecommons.aku.edu/pakistan_fhs_ mc_women_childh ealth_paediatr/262.

6. Bhutta ZA, Gazdar H., Haddad L. Seeing the unseen: Breaking the logjam of undernutrition in Pakistan. IDS Bull. 2013; 44(3): 1-9. doi: 10.1111/1759-5436.12025.
7. The Open University [Internet]. Nutrition Module: 3. Nutritional Requirements Throughout the Lifecycle. Available from: https://www.open.edu/ openlearncreate/mod/ oucontent/view.php? $\mathrm{id}=316$.

8. Maleta K. Undernutrition. Malawi Med J. 2006; 18 (4): $189-205$

9. Baroni L, Googi S, Battaglino R, Berveglieri M, Fasan I, Filippin D, et al. Vegan Nutrition for Mothers and Children: Practical Tools for Healthcare Providers. Nutrients. 2018; 11(1). pii: E5. doi: 10.3390/nu11010005

10. United Nations Office on Drugs and Crimes. Trafficking in Persons. United Nations Publications. 2018. Available from: https://www.unodc.org/ unodc/data-and-analysis /glotip.html.

11. University of New Mexico. Stress during pregnancy affects the size of the baby: Growth outcome opposite due to adversity at the beginning and end of gestation period. Science Daily.[Internet]. 28 November 2017. Available from: https://www.sciencedaily.com /releases/ 2017/11/171128185924.htm

12. Arif GM, Nazir S, Satti MN, Farooq S. Child Malnutrition in Pakistan: Trends and Determinants. Pak Inst Develop Econ. July 2012.

13. Rahman A. Significant Risk Factors for Childhood Malnutrition: Evidence from an Asian Developing Country. Sci J Public Health. 2016; 4(1-1): 16-27. doi:10.11648/j.sjph.s. 2016040101.14

14. Rahman M. Association between order of birth and chronic malnutrition of children: a study of nationally representative Bangladeshi sample. Cad. Saude Publica. 2016; 32(2): e00011215 doi:10.1590/0102-311X00011215.

15. Rai R, Singh DK. Maternal Profile of Children with Severe Acute Malnutrition. Indian Paediatrics. 2015; 52(4): 344.

16. Abera L, Dejene T, Laelag T. Prevalence of malnutrition and associated factors in children aged 6-59 months among rural dwellers of damot gale district, south Ethiopia: community based cross sectional study. Int J Equity Health. 2017; 16(1): 111. doi: 10.1186/s12939-017-0608-9

17. Habyarimana F, Zewotir T, Ramroop S. Key determinants of malnutrition of children under five years of age in Rwanda: Simultaneous measurement of three anthropometric indices. Afr Popul Stud. 2016; 30(2): 2328-40

18. Tigga PL, Sen J. Maternal Body Mass Index is Strongly Associated with Children Z-Scores for Height and BMI. J Anthropol. 2016; 1-10. doi:10.1155/2016/6538235.

19. Hasan MT, Soares Magalhaes RJ, Williams GM, Mamun AA. Long-term changes in childhood 
malnutrition are associated with long-term changes in maternal BMI: evidence from Bangladesh., 1996-2011. Am J Clin Nutr. 2016; 104 (4): 1121-27. doi:10.3945/ajcn.115.111773

20. Talukder A. Factors Associated with Malnutrition among Under-Five Children: Illustration using Bangladesh Demographic and Health Survey, 2014 Data. Children(Basel). 2017; 4 (10). pii: E88. doi:10.3390/children4100088.

21. Ndemwa M, Wanyua S, Kaneko S, Karama M, Anselimo M. Nutritional status and association of demographic characteristics with malnutrition among children less than 24 months in Kwale County, Kenya. Pan Afr Med J. 2017; 28: 265. doi:10.11604/pamj. 2017.28.265.12703

22. Kerkez FI, Tutal V, Akcinar F. malnutrition/obesity prevalence among children between the ages of 3 and 6 and mother-child BMI relation. Int $\mathrm{J}$ Acad
Res (Part A). 2013; 5(5): 211-4. doi:10.7813/2075 $-4124.2013 / 5-5 / A .30$

23. Youngmeyer D. UNICEF supports fight against child malnutrition in flood-ravaged districts of Pakistan. (Pakistan flood crisis, one year on). UNICEF for every child [Internet]. August 02, 2011. Available from: https://www.unicef.org/ nutrition/ Pakistan_59452.html

24. Teixeira $\mathrm{VH}$, Moreira $\mathrm{P}$. Maternal food intake and socioeconomic status to tackle childhood malnutrition. J Pediatr (Rio J). 2016; 92(6): 546-8. doi: 10.1016/j.jped.2016. 08.002.

25. Ravaoarisoa L, Randriamanantsaina L, Rakotonirina J, Rakotomanga JD, Donnen P, Dramaix M. Socioeconomic determinants of malnutrition among mothers in the Amoron'i Mania region of Madagascar: a cross-sectional study. BMC Nutr. 2018; 4: 6. doi:10.1186/s40795-018-0212-4

AUTHOR AFFILIATION:

\section{Dr. Bindia Kailash}

Resident, Department of Paediatric Liaquat University of Medical \& Health Sciences (LUMHS), Jamshoro, Sindh-Pakistan.

\section{Dr. Salma Shaikh}

Professor, Department of Paediatric

LUMHS, Jamshoro, Sindh-Pakistan.

\section{Dr. Muhammad Nadeem Chohan}

(Corresponding Author)

Assistant Professor, Department of Paediatrics

LUMHS, Jamshoro, Sindh-Pakistan.

Email: nadeem.chohan@lumhs.edu.pk

\section{Dr. Muhammad Hanif}

Chief Medical Officer, Department of Paediatric

LUMHS, Jamshoro, Sindh-Pakistan.

\section{Dr. Mushtaque Ali Shah}

Senior Registrar, Department of Paediatric

LUMHS, Jamshoro, Sindh-Pakistan. 